\title{
Farelo integral de arroz parboilizado submetido a armazenamento prolongado para alimentação de codornas de corte
}

\author{
Nadja Naiara Pereira Farias(1), Ednardo Rodrigues Freitas(1), Regina Patrícia de Souza Xavier(1), \\ Nádia de Melo Braz ${ }^{(1)}$, Thais Cruz Lopes Tavares ${ }^{(1)}$, Carlos Weiber Silva Figueiredo ${ }^{(1)}$, \\ Danilo Rodrigues Fernandes ${ }^{(1)}$ e Germano Augusto Jerônimo do Nascimento(1)
}

\begin{abstract}
(1)Universidade Federal do Ceará, Centro de Ciências Agrárias, Departamento de Zootecnia, Campus do Pici, Avenida Mister Hull, no 2.977 , Caixa Postal 12168, CEP 60021970 Fortaleza, CE, Brasil. E-mail: nadja_naiara@hotmail.com, ednardo@ufc.br, r_patriciasx@hotmail.com, nadia_zootec@yahoo.com.br, thaiscltavares@gmail.com, weibers@hotmail.com, danilo_zoo@hotmail.com, germanoaugusto@ufc.br
\end{abstract}

Resumo - O objetivo deste trabalho foi avaliar a estabilidade oxidativa do farelo integral de arroz parboilizado (FIAP) durante o armazenamento e os efeitos do seu uso na alimentação de codornas de corte. Foram utilizados 245 animais com sete dias de idade, de ambos os sexos, distribuídos em delineamento inteiramente casualizado, com cinco tratamentos, em arranjo fatorial $2 \times 2+1$, e sete repetições de sete aves. Avaliaram-se os seguintes tratamentos: dieta controle, sem adição de FIAP; e níveis de inclusão, na dieta controle, de 10 e $20 \%$ de FIAP armazenado por 180 dias (FIAPA) ou de FIAP novo (FIAPN). Houve oxidação lipídica do FIAP durante o armazenamento, e o índice de acidez foi de 4,25 e 63,50 (\% em ácido oleico) e o de peróxido foi de 15,64 e $38,28 \mathrm{meq} \mathrm{kg}^{-1}$ para FIAPN e FIAPA, respectivamente. A inclusão do FIAP resultou em menor digestibilidade da matéria seca e do nitrogênio e em maior valor de energia metabolizável da ração, em comparação à ração controle. A inclusão de $20 \%$ de FIAPA resultou em menor energia metabolizável da ração do que a adição do FIAPN. As inclusões não influenciaram desempenho, características da carcaça, pesos relativos do fígado e do pâncreas, e crescimento e qualidade óssea. O FIAPA, mesmo com rancidez, pode ser utilizado na alimentação de codornas de corte em níveis de até $20 \%$ de inclusão.

Termos para indexação: Coturnix coturnix, características de carcaça, desempenho produtivo, estabilidade oxidativa, rancidez hidrolítica, rancidez oxidativa.

\section{Parboiled rice bran subjected to prolonged storage for meat quail feeding}

\begin{abstract}
The objective of this work was to evaluate the oxidative stability of parboiled rice bran (PRB) during storage and the effects of its use on meat quail feeding. Two hundred forty-five animals, with seven days of age, of both sexes, were used, distributed in a completely randomized design, with five treatments in a $2 \times 2+1$ factorial arrangement and seven replicates of seven chicks. The following treatments were evaluated: control diet, without PRB; and inclusion levels of 10 and $20 \%$ of 180 -day-storaged PRB (SPRB) or of new PRB (NPRB) in the control diet. There was lipid oxidation of PRB during storage, the acid index was 4.25 and 63.50 (\% as oleic acid) and the peroxide index was 15.64 and 38.28 meq kg$^{-1}$ for NPRB and SPRB, respectively. The inclusion of PRB resulted in lower dry matter and nitrogen digestibility and in higher metabolizable energy value of feed when compared to the control diet. The inclusion of $20 \%$ SPRB resulted in lower metabolizable energy of feed than the addition of NPRB. The inclusions did not influence performance, carcass traits, relative weights of the liver and pancreas, and bone growth and quality. The SPRB, although rancid, can be used as feed for meat quail at levels up to $20 \%$ inclusion.
\end{abstract}

Index terms: Coturnix coturnix, carcass traits, productive performance, oxidative stability, hydrolytic rancidity, oxidative rancidity.

\section{Introdução}

O aproveitamento de subprodutos da agroindústria regional é alternativa para melhorar a oferta de alimentos que possam reduzir os custos de produção sem afetar o desempenho das aves (Lopes et al., 2011). No Ceará, alguns subprodutos da agroindústria, como farelo e quebrados de arroz, resultantes do beneficiamento do arroz para o consumo humano, apresentam composição química que os potencializam como ingredientes para as rações de aves.

O farelo integral de arroz é rico em vitaminas, aminoácidos e ácidos graxos insaturados (Samli et al., 2006). No entanto, a presença de fatores 
antinutricionais, tais como fitato, lipases e substâncias antiproteolíticas, limita a utilização do farelo integral de arroz na alimentação das aves (Piyaratne et al., 2009). Além disso, o farelo de arroz é propenso a desenvolver rancidez em razão da elevada percentagem de gordura e enzimas lipolíticas, o que torna o farelo muito instável durante o armazenamento (Mujahid et al., 2003).

Os ácidos graxos liberados pela hidrólise dos triglicerídeos durante o armazenamento proporcionam sabor ácido e desagradável, o que compromete a utilização do farelo na alimentação animal (Pestana et al., 2009). Nesse contexto, alguns pesquisadores tem relatado a necessidade da estabilização do farelo logo após a sua obtenção, e o processamento térmico tem sido o método mais utilizado para inativação das lipases e produção de farelo de arroz integral estável, sem aumento dos ácidos graxos livres durante o armazenamento (Mujahid et al., 2003; Oliveira et al., 2012).

Diferentemente do beneficiamento tradicional, no processo de parboilização, o grão de arroz é submetido ao calor sob pressão antes de ser descascado e polido, o que ocasiona mudanças físicas e químicas no grão polido e no farelo (Dors et al., 2009). De acordo com Lacerda et al. (2010), o processo de parboilização aumenta o valor nutritivo do farelo e, por se tratar de processo térmico, acarreta a inativação das lipases presentes no farelo, o que resulta em ingrediente de maior estabilidade no armazenamento. $\mathrm{O}$ aumento no consumo do arroz que passa por parboilização tem aumentado a oferta do farelo oriundo desse processamento.

O objetivo deste trabalho foi avaliar a estabilidade oxidativa do farelo integral de arroz parboilizado (FIAP) durante o armazenamento (FIAPA) e os efeitos do seu uso na alimentação de codornas de corte.

\section{Material e Métodos}

O experimento foi conduzido no Setor de Avicultura do Departamento de Zootecnia do Centro de Ciências Agrárias da Universidade Federal do Ceará, no período de 20 de junho a 1 de agosto de 2011.

Foram utilizadas 245 codornas (Coturnix coturnix) de corte com sete dias de idade, de ambos os sexos, distribuídas em delineamento inteiramente casualizado, com cinco tratamentos, sete repetições e sete aves por unidade experimental. Os tratamentos foram dispostos em arranjo fatorial $2 \times 2+1$, em que foram avaliados os fatores: armazenamento (farelo armazenado e novo) e nível de inclusão (10 e 20\%), além de um tratamento adicional (ração controle).

Para a obtenção dos farelos a serem estudados, inicialmente, foi adquirido um lote de $100 \mathrm{~kg}$ de farelo integral de arroz parboilizado (FIAP) logo após o beneficiamento industrial. Esse farelo, acondicionado em saco de ráfia, foi estocado sobre tablado de madeira, em local coberto, seco, bem ventilado e fora do alcance da luz, durante 180 dias, tendo-se obtido o farelo integral de arroz parboilizado armazenado (FIAPA). Ao término desse período, foi adquirido um novo lote de $100 \mathrm{~kg}$ de FIAP, que constituiu o farelo de arroz integral parboilizado novo (FIAPN). Os dois farelos foram adquiridos na mesma empresa de processamento, a partir de um mesmo lote de arroz.

Os dois farelos foram encaminhados para análise da estabilidade lipídica, por meio da determinação dos índices de acidez (\% em ácido oleico) e de peróxido (meq kg-1) dos farelos (Instituto Adolfo Lutz, 2008). Independentemente dos resultados obtidos para oxidação lipídica, estes foram utilizados para composição das rações experimentais (Tabela 1), que foram calculadas para serem isoenergéticas e isonutritivas, segundo as exigências nutricionais para codornas do NRC (Nutrient requirements of poultry, 1994), tendo-se considerado os dados de composição dos alimentos propostos por Rostagno et al. (2011).

Um total de 350 codornas com um dia de idade foram pesadas e alojadas em um círculo de proteção, onde contaram com fonte de calor, bebedouros de pássaros adaptados e comedouros tipo bandeja, suficientes para o total de aves. No período de 1 a 7 dias de idade, as aves receberam ração controle e foram manejadas conforme recomendações técnicas para o período. No sétimo dia de idade, as aves foram novamente pesadas e distribuídas, de acordo com o peso, nos diferentes tratamentos, de modo a se obterem parcelas com o mesmo peso médio, conforme as recomendações de Sakomura \& Rostagno (2007) para a montagem de ensaios com aves. Nessa fase, as aves de cada parcela foram alojadas em gaiolas de arame galvanizado $(52 \times 26 \times 20 \mathrm{~cm})$, que continham comedouros do tipo calha e bebedouros de pássaros adaptados. Nessa idade, as aves foram vacinadas contra a doença de Newcastle, por via ocular. 
No período de criação, as aves receberam 24 horas de luz (natural + artificial). A iluminação artificial do galpão foi realizada com lâmpadas fluorescentes de $40 \mathrm{~W}$, distribuídas a uma altura de $2,40 \mathrm{~m}$ do piso, para permitir iluminação uniforme para todas as aves. As variáveis ambientais de temperatura e umidade relativa do ar no interior do galpão foram medidas com termohigrômetro. Os dados foram registrados diariamente, e as leituras, realizadas às 8 e $16 \mathrm{~h}$.

Tabela 1. Composição das rações experimentais para codornas (Coturnix coturnix) de corte de 7 a 42 dias de idade $^{(1)}$.

\begin{tabular}{|c|c|c|c|c|c|}
\hline \multirow{2}{*}{$\begin{array}{l}\text { Ingrediente } \\
(\mathrm{kg})\end{array}$} & \multirow[t]{2}{*}{ Controle } & \multicolumn{2}{|c|}{ FIAPN (\%) } & \multicolumn{2}{|c|}{ FIAPA (\%) } \\
\hline & & 10 & 20 & 10 & 20 \\
\hline Milho & 52,10 & 41,94 & 31,77 & 41,94 & 31,77 \\
\hline FIAPN & 0,00 & 10,00 & 20,00 & 0,00 & 0,00 \\
\hline FIAPA & 0,00 & 0,00 & 0,00 & 10,00 & 20,00 \\
\hline Farelo de soja (45\%) & 42,99 & 41,93 & 40,86 & 41,93 & 40,86 \\
\hline Calcário calcítico & 1,20 & 1,25 & 1,29 & 1,25 & 1,29 \\
\hline Óleo de soja & 1,91 & 3,20 & 4,51 & 3,20 & 4,51 \\
\hline Fosfato monobicálcico & 0,94 & 0,82 & 0,71 & 0,82 & 0,71 \\
\hline Suplemento $\mathrm{MV}^{(2)}$ & 0,40 & 0,40 & 0,40 & 0,40 & 0,40 \\
\hline Sal comum & 0,44 & 0,44 & 0,44 & 0,44 & 0,44 \\
\hline DL-metionina & 0,02 & 0,02 & 0,02 & 0,02 & 0,02 \\
\hline Total & 100,00 & 100,00 & 100,00 & 100,00 & 100,00 \\
\hline \multicolumn{6}{|c|}{ Nível nutricional calculado ${ }^{(3)}$} \\
\hline EM (kcal kg-1) & 2.900 & 2.900 & 2.900 & 2.900 & 2.900 \\
\hline Proteína bruta (\%) & 23,80 & 23,80 & 23,80 & 23,80 & 23,80 \\
\hline Matéria seca (\%) & 87,40 & 87,59 & 88,39 & 87,59 & 88,39 \\
\hline Extrato etéreo $(\%)$ & 4,49 & 6,85 & 9,25 & 6,85 & 9,25 \\
\hline Fibra bruta $(\%)$ & 3,45 & 3,99 & 4,54 & 3,99 & 4,54 \\
\hline FDA $(\%)$ & 5,35 & 6,16 & 6,97 & 6,16 & 6,97 \\
\hline FDN (\%) & 12,08 & 12,86 & 13,65 & 12,86 & 13,65 \\
\hline Cálcio (\%) & 0,80 & 0,80 & 0,79 & 0,80 & 0,79 \\
\hline Fósforo disponível (\%) & 0,30 & 0,30 & 0,30 & 0,30 & 0,30 \\
\hline Sódio $(\%)$ & 0,22 & 0,22 & 0,22 & 0,22 & 0,22 \\
\hline Lisina total $(\%)$ & 1,32 & 1,32 & 1,33 & 1,32 & 1,33 \\
\hline Metionina + CT (\%) & 0,87 & 0,87 & 0,87 & 0,87 & 0,87 \\
\hline Metionina total (\%) & 0,50 & 0,50 & 0,50 & 0,50 & 0,50 \\
\hline Treonina total (\%) & 0,93 & 0,92 & 0,92 & 0,92 & 0,92 \\
\hline Triptofano total (\%) & 0,30 & 0,30 & 0,30 & 0,30 & 0,30 \\
\hline
\end{tabular}

${ }^{(1)}$ Controle, ração sem farelo integral de arroz parboilizado; FIAPN, farelo integral de arroz parboilizado novo; FIAPA, farelo integral de arroz parboilizado armazenado. ${ }^{(2)}$ Composição do suplemento mineral e vitamínico (MV) por kg do produto: ácido fólico, $138 \mathrm{mg}$; pantotenato de cálcio, $2.750 \mathrm{mg}$; antioxidante, $500 \mathrm{mg}$; biotina, $13,80 \mathrm{mg}$; cobalto, $25 \mathrm{mg}$; cobre, $2.500 \mathrm{mg}$; colina, $111.450 \mathrm{mg}$; ferro, $6.250 \mathrm{mg}$; iodo, $260 \mathrm{mg}$; manganês, $13.000 \mathrm{mg}$; metionina, $300 \mathrm{~g}$; niacina, $6.875 \mathrm{mg}$; piridoxina, $550 \mathrm{mg}$; colistina, $750 \mathrm{mg}$; riboflavina, $1.375 \mathrm{mg}$; selênio, $45 \mathrm{mg}$; tiamina, $550 \mathrm{mg}$; vitamina A, $2.150 .000 \mathrm{UI}$; vitamina B12, $2.750 \mathrm{mg}$; vitamina D3, $555.000 \mathrm{UI}$; vitamina E, $2.750 \mathrm{UI}$; vitamina $\mathrm{K}, 400 \mathrm{mg}$; zinco, $11.100 \mathrm{mg}$; silicatos, $20.000 \mathrm{mg}$. ${ }^{(3)} \mathrm{EM}$, energia metabolizável; FDA, fibra em detergente ácido; FDN, fibra em detergente neutro; CT, cistina total.
No final do período experimental, foram calculadas as médias das temperaturas máxima e mínima e as médias da umidade relativa do ar. Durante o experimento, as médias das temperaturas máxima e mínima registradas no galpão foram de 31,25 e $25,10^{\circ} \mathrm{C}$, respectivamente. Para a umidade relativa do ar, o valor médio foi de $66 \%$.

Durante todo o período experimental, de 7 a 42 dias de idade, as rações e a água foram fornecidas à vontade, e os comedouros e os bebedouros, abastecidos duas vezes ao dia, às 8 e $16 \mathrm{~h}$. Os parâmetros de desempenho avaliados foram: consumo de ração (g por ave), ganho de peso ( $\mathrm{g}$ por ave) e conversão alimentar $\left(\mathrm{g} \mathrm{g}^{-1}\right)$, tendose corrigido as variáveis para mortalidade (Sakomura \& Rostagno, 2007).

Para avaliar a digestibilidade dos nutrientes, procedeu-se à coleta total das excretas (Sakomura \& Rostagno, 2007) no período de 14 a 17 dias de idade das aves. Antes do início da fase de alimentação experimental, as codornas foram submetidas a jejum alimentar de 2 horas para esvaziar o trato gastrintestinal, tendo-se coletado apenas as excretas provenientes da ração consumida durante o ensaio. Esse mesmo procedimento foi realizado para determinar o final do período de coleta. As excretas de cada unidade experimental foram coletadas duas vezes ao dia, no início da manhã (às $8 \mathrm{~h}$ ) e no final da tarde (às 16h), em bandejas cobertas com plástico, colocadas sob cada gaiola. Após as coletas, as excretas foram colocadas em bandejas de papel alumínio e levadas ao laboratório para pré-secagem em estufa de ventilação forçada de ar, a $55^{\circ} \mathrm{C}$, por 72 horas. Em seguida, foram trituradas em moinho tipo faca com malhas de $1 \mathrm{~mm}$ e colocadas em potes de plástico.

As amostras das excretas e das rações foram encaminhadas para determinação do teor de massa de matéria seca (MS), nitrogênio (N) e energia bruta (EB) (Silva \& Queiroz, 2002). Com base nos resultados das análises, foram determinados os coeficientes de metabolização aparente da MS (CMMS), do N (CMN) e da EB (CMEB), bem como os valores de energia metabolizável aparente (EMA) e energia metabolizável aparente corrigida (EMAn), segundo Sakomura \& Rostagno (2007).

Ao final do período experimental (42 dias de idade), duas aves de cada parcela, um macho e uma fêmea, foram selecionadas para abate e avaliação das características de carcaça. Foram selecionadas aves 
com peso médio semelhante ao da parcela, que, após jejum alimentar de 8 horas, foram abatidas, depenadas e evisceradas. Após a pesagem do fígado e do pâncreas e a pesagem da carcaça sem o pescoço, dos pés e das vísceras comestíveis, realizaram-se os cortes.

$\mathrm{O}$ rendimento de carcaça (\%) e os pesos relativos (\%) do fígado e do pâncreas foram calculados em relação ao peso vivo das aves, e os rendimentos (\%) de peito e coxa+sobrecoxa, em relação ao peso da carcaça eviscerada.

Para a retirada da tíbia, as duas coxas de cada ave foram retiradas e congeladas em freezer, a $-20^{\circ} \mathrm{C}$, para posterior análise. $\mathrm{O}$ descongelamento foi realizado em geladeira, a $4^{\circ} \mathrm{C}$, por 24 horas, e cada coxa, devidamente identificada, foi submetida ao cozimento em água fervente por $10 \mathrm{~min}$. Em seguida, foram retirados os tecidos que envolvem o osso, com uso de bisturis. Com os ossos devidamente preparados, foram avaliados: peso (mg), em balança eletrônica com precisão de $0,01 \mathrm{~g}$; e comprimento $(\mathrm{mm})$, com auxílio de paquímetro digital. Com esses dados, obteve-se o índice de Seedor $\left(\mathrm{mg} \mathrm{mm}^{-1}\right)$, por meio da divisão do peso do osso (mg) pelo seu comprimento (mm) (Seedor et al., 1991).

As tíbias esquerdas foram utilizadas para determinação da resistência $\left(\mathrm{kgf} \mathrm{cm}^{-2}\right)$ e da deformidade $(\mathrm{mm})$ óssea, em laboratório, com auxílio de prensa mecânica triaxial Testop/Ronald top (Indústria e Comércio Ronald Top Ltda., Rio de Janeiro, RJ), com capacidade de $150 \mathrm{~kg}$. Os ossos foram colocados em posição horizontal sobre um suporte de madeira, apoiados em suas extremidades, e, em seguida, foi aplicada uma força de compressão exercida por pistão, no centro de cada osso. A velocidade de descida do pistão foi de $1,23 \mathrm{~mm} \mathrm{~min}^{-1}$. A quantidade máxima de força aplicada no osso até sua ruptura foi considerada a resistência à quebra $\left(\mathrm{kgf} \mathrm{cm}^{-2}\right)$, que foi mensurada com extensômetro digital, modelo 543-682 (Mitutoyo Sul Americana Ltda., São Paulo, SP). A deformidade do osso $(\mathrm{mm})$ foi medida por meio de registro da flexão de cada osso em relação a sua posição horizontal, até antes da sua ruptura pela ação da força aplicada, em extensômetro analógico, modelo 2046-s (Mitutoyo Sul Americana Ltda., São Paulo, SP).

As tíbias direitas foram levadas ao laboratório para realização da pré-secagem em estufa de ventilação forçada de ar, a $55^{\circ} \mathrm{C}$, por 72 horas. Em seguida, foram trituradas em moinho tipo bola, colocadas em potes de plástico e encaminhadas para determinação de matéria seca e matéria mineral (Silva \& Queiroz, 2002).

As análises estatísticas dos dados foram realizadas com uso do programa SAS, versão 8.2 (SAS Intitute, Cary, NC, EUA). Os dados foram submetidos à análise de variância para avaliar o efeito dos tratamentos e testar o fatorial. O teste de Dunnett, a 5\% de probabilidade, foi utilizado para comparar o tratamento controle a cada um dos demais tratamentos, e o teste $\mathrm{t}$, a $5 \%$ de probabilidade, para comparar os fatores avaliados armazenamento e nível de inclusão.

\section{Resultados e Discussão}

Os índices de acidez obtidos, respectivamente, para FIAPN e FIAPA, foram de 4,25 e $63,50 \%$ em ácido oleico; e os índices de peróxidos obtidos, respectivamente, para FIAPN e FIAPA, foram de 15,64 e 38,28 meq $\mathrm{kg}^{-1}$.

O FIAP sofreu reações de hidrólise durante o armazenamento por 180 dias, uma vez que houve aumento de aproximadamente 15 vezes no índice de acidez do FIAPA. Silva et al. (2006), ao avaliar a estabilidade do farelo de arroz parboilizado, verificaram que a acidez desse farelo armazenado por quatro meses foi apenas 1,65 vezes maior que a do farelo de arroz parboilizado novo. Por sua vez, Pestana et al. (2009) relataram que o índice de acidez do farelo de arroz parboilizado foi menor $(0,64 \%$ em ácido oleico $)$ que o índice de acidez do farelo de arroz comum $(1,40 \%$ em ácido oleico), o que confirma o efeito do processo de parbolização na estabilização do farelo de arroz.

Em relação ao índice de peróxido, observou-se que o FIAPA foi superior em torno de 2,5 vezes ao FIAPN, o que pode ser relacionado à continuidade de reações oxidativas durante o período de armazenamento. Pestana et al. (2009) observaram que o farelo de arroz parboilizado apresentou níveis muito baixos de peróxidos $\left(1,22 \mathrm{meq} \mathrm{kg}^{-1}\right)$ e associaram o resultado obtido à utilização de altas temperaturas durante o processo de parboilização e, consequentemente, à inativação das enzimas lipolíticas presentes no farelo.

Como verificado, com o aumento dos índices de acidez e peróxidos, os processos de rancificação do farelo de arroz parboilizado ocorrem durante o armazenamento, o que deve ser considerado para seu uso na alimentação animal.

Quanto aos coeficientes de metabolização e da energia metabolizável das rações experimentais, houve 
diferenças significativas entre os tratamentos para CMMS, CMN e energia metabolizável (Tabela 2). $\mathrm{Na}$ comparação das médias pelo teste de Dunnet, a $5 \%$ de probabilidade, observou-se que a ração controle apresentou CMMS e CMN significativamente maiores que os das rações contendo FIAP. Os valores de EMA e EMAn determinados para a ração controle foram menores que os dos demais tratamentos; entretanto, quanto à EMA, a diferença foi significativa apenas para a adição de $20 \%$ de FIAPN, e, quanto à EMAn, houve diferença significativa para a inclusão de $20 \%$ de FIAPA e 10 ou $20 \%$ de FIAPN.

Não houve interação significativa do nível de inclusão e do tipo de FIAP sobre os coeficientes de metabolização, mas sim para os valores de energia metabolizável (Tabela 2). Também constatou-se que, independentemente do tipo de FIAP, houve redução significativa no CMMS, com o aumento de 10 para $20 \%$ de inclusão do FIAP na ração. O CMN foi menor

Tabela 2. Coeficiente de digestibilidade e valor energético das rações de codornas (Coturnix coturnix) de corte com diferentes níveis de inclusão de farelo integral de arroz parboilizado novo (FIAPN) ou armazenado (FIAPA) por 180 dias $^{(1)}$.

\begin{tabular}{lccccc}
\hline Tratamentos & $\begin{array}{c}\text { CMMS } \\
(\%)\end{array}$ & $\begin{array}{c}\text { CMN } \\
(\%)\end{array}$ & $\begin{array}{c}\text { CMEB } \\
(\%)\end{array}$ & $\begin{array}{c}\text { EMA } \\
\left(\mathrm{kcal} \mathrm{kg}^{-1} \mathrm{MS}\right)\end{array}$ & $\begin{array}{c}\text { EMAn } \\
\left(\mathrm{kcal} \mathrm{kg}^{-1} \mathrm{MS}\right)\end{array}$ \\
\hline Controle & 73,23 & 60,44 & 77,58 & 3.527 & 3.283 \\
$10 \%$ FIAPA & $70,51^{*}$ & 57,29 & 77,00 & 3.592 & 3.356 \\
$20 \%$ FIAPA & $67,16^{*}$ & $53,96^{*}$ & 74,97 & 3.606 & $3.419^{*}$ \\
$10 \%$ FIAPN & $70,31^{*}$ & $47,96^{*}$ & 76,34 & 3.564 & $3.439^{*}$ \\
$20 \%$ FIAPN & $68,44^{*}$ & $51,05^{*}$ & 76,29 & $3.734^{*}$ & $3.567^{*}$ \\
\hline Média & 69,96 & 54,05 & 76,45 & 3.603 & 3.412 \\
CV (\%) & 2,09 & 6,90 & 2,03 & 2,01 & 1,95 \\
\hline Nível de inclusão & & & & & \\
$10 \%$ & $70,41 \mathrm{a}$ & $54,05 \mathrm{a}$ & $76,67 \mathrm{a}$ & $3.578 \mathrm{~b}$ & $3.357 \mathrm{~b}$ \\
$20 \%$ & $67,80 \mathrm{~b}$ & $52,51 \mathrm{a}$ & $75,63 \mathrm{a}$ & $3.670 \mathrm{a}$ & $3.493 \mathrm{a}$ \\
\hline Alimento & & & & & \\
FIAPA & $68,96 \mathrm{a}$ & $55,75 \mathrm{a}$ & $76,06 \mathrm{a}$ & $3.598 \mathrm{a}$ & $3.385 \mathrm{~b}$ \\
FIAPN & $69,44 \mathrm{a}$ & $50,93 \mathrm{~b}$ & $76,31 \mathrm{a}$ & $5.642 \mathrm{a}$ & $3.454 \mathrm{a}$ \\
\hline Valor p & & & & & \\
$\quad$ Tratamento & 0,001 & 0,001 & 0,074 & 0,005 & 0,001 \\
$\quad$ Nível & 0,002 & 0,215 & 0,072 & 0,002 & 0,001 \\
Alimento & 0,413 & 0,006 & 0,647 & 0,107 & 0,006 \\
Nível x Alimento & 0,214 & 0,156 & 0,087 & 0,007 & 0,004 \\
\hline
\end{tabular}

${ }^{(1)}$ Médias seguidas de letras iguais, nas colunas, não diferem pelo teste t, a $5 \%$ de probabilidade. *Difere em relação ao controle pelo teste de Dunnet, a $5 \%$ de probabilidade. CMMS, coeficiente de digestibilidade da matéria seca; CMN, coeficiente de digestibilidade do nitrogênio; CMEB, coeficiente de digestibilidade da energia bruta; EMA, energia metabolizável aparente; EMAn, energia metabolizável aparente corrigida para o balanço de nitrogênio; Controle, sem farelo integral de arroz parboilizado. para o FIAPN, e o CMEB não foi influenciado pelo nível ou pelo tipo de FIAP da ração.

Com o desdobramento da interação para os valores de energia metabolizável (Tabela 3), não foi observada diferença significativa nos valores de EMA e EMAn das rações com $10 \%$ de FIAPA ou FIAPN; porém, com o nível de $20 \%$ de inclusão, os valores de EMA e EMAn das rações que continham FIAPN foram significativamente maiores que os obtidos para FIAPA. Dessa forma, ao se comparar o efeito do aumento do nível de cada FIAP nas rações, constatou-se aumento significativo de EMA e EMAn com uso do FIAPN e apenas de EMAn com o FIAPA.

Há relatos de que o aumento da fração fibrosa pela presença de polissacarídeos não amiláceos e de outros fatores antinutricionais presentes no farelo de arroz pode promover redução no aproveitamento dos nutrientes da ração quando esse ingrediente é adicionado (Gallinger et al., 2004; Piyaratne et al., 2009). Porém, no presente trabalho, embora tenha havido redução nos coeficientes de digestibilidade da matéria seca e do nitrogênio com a inclusão do FIAP, houve aumento nos valores de energia metabolizável das rações que o continham.

O aumento da energia metabolizável com a adição de FIAP pode ser associado ao aumento da proporção e da disponibilidade lipídica nas rações que o continham. Segundo Pestana et al. (2009), a concentração de gordura no FIAP é grande e o processo de parboilização aumenta a exposição dos lipídeos no farelo (Dors et al., 2009). Contudo, uma possível subestimação

Tabela 3. Desdobramento da interação para os valores energéticos das rações de codornas (Coturnix coturnix) de corte contendo diferentes níveis de farelo integral de arroz parboilizado novo (FIAPN) ou armazenado (FIAPA) por 180 dias $^{(1)}$.

\begin{tabular}{|c|c|c|c|}
\hline \multirow{2}{*}{$\begin{array}{l}\text { Nível de } \\
\text { inclusão }\end{array}$} & \multicolumn{2}{|c|}{ Tipo de farelo de arroz } & \multirow[t]{2}{*}{ Média } \\
\hline & FIAPN & FIAPA & \\
\hline & \multicolumn{3}{|c|}{ Energia metabolizável aparente } \\
\hline $10 \%$ & 3.564Ba & $3.592 \mathrm{Aa}$ & 3.578 \\
\hline $20 \%$ & $3.734 \mathrm{Aa}$ & $3.606 \mathrm{Ab}$ & 3.670 \\
\hline \multirow[t]{2}{*}{ Média } & 3.649 & 3.599 & \\
\hline & \multicolumn{3}{|c|}{ Energia metabolizável aparente corrigida } \\
\hline $10 \%$ & $3.439 \mathrm{Ba}$ & 3.356Ba & 3.357 \\
\hline $20 \%$ & 3.567Aa & $3.419 \mathrm{Ab}$ & 3.493 \\
\hline Média & 3.462 & 3.388 & \\
\hline
\end{tabular}

${ }^{(1)}$ Médias seguidas de letras iguais, maiúsculas nas colunas e minúsculas nas linhas, não diferem pelo teste $\mathrm{t}$, a $5 \%$ de probabilidade. 
do valor de energia metabolizável do FIAP, ao se considerar os valores tabelados por Rostagno et al. (2011), contribuiu para uma maior adição de óleo nas rações. Tendo em vista que as gorduras são grandes fornecedoras de energia e a sua adição nas rações traz benefícios decorrentes do efeito extra calórico, que consiste no aumento da disponibilidade dos nutrientes de outros ingredientes da ração (Freitas et al., 2006). Assim, a maior presença de gordura contribuiu para aumentar a energia metabolizável das rações à medida que se adicionou o FIAP.

O aumento de 10 para $20 \%$ de inclusão do FIAPA não promoveu aumento da energia metabolizável da ração na mesma proporção verificada para a adição do FIAPN. Essa diferença pode ter sido resultante dos efeitos dos processos de hidrólise e oxidação lipídica durante o armazenamento, conforme mostrado com o aumento dos índices de acidez e peróxidos. Esse resultado corrobora os obtidos por Chaiyasit et al. (2007), que afirmaram que a lipoperoxidação diminui o valor energético do alimento, em decorrência da destruição dos ácidos graxos. Mujahid et al. (2003) relataram menores valores de digestibilidade da gordura com o tempo de armazenamento do farelo de arroz; no entanto, a magnitude desse efeito depende do nível de inclusão e do processamento térmico ao qual o farelo foi submetido.

$\mathrm{Na}$ análise dos dados de desempenho, observou-se que o consumo de ração, o ganho de peso e a conversão alimentar não foram influenciados pelos tratamentos (Tabela 4). O consumo voluntário de alimento pelas aves pode ser influenciado por diversos fatores, entre eles, o nível de energia e a palatabilidade da ração (Baião \& Lara, 2005). Portanto, pode-se inferir que, como o consumo de ração não diferiu significativamente entre os tratamentos, as modificações nos valores observados de energia metabolizável da ração e a presença de substâncias geradas durante a rancificação do FIAPA, que poderia alterar a palatabilidade da ração, não foram suficientes para modificar significativamente a ingestão de ração. Uma vez que não houve diferença significativa no ganho de peso das aves e este foi proporcional à ingestão de alimento, os valores de conversão alimentar não diferiram significativamente.

Os resultados de desempenho das codornas alimentadas com FIAPN ou FIAPA diferem em parte dos relatados para a utilização do farelo de arroz para frangos (Gallus gallus) ou codornas de corte. Gallinger et al. (2004) concluíram que inclusões de farelo de arroz integral na ração de frangos de corte acima de $20 \%$ produzem reduções significativas no ganho de peso, o que prejudica a conversão alimentar. Filgueiras (2012), que trabalhou com codornas de corte, relatou que a inclusão de farelo integral de arroz parboilizado em níveis acima de 5\% promoveu redução linear no consumo de ração e ganho de peso das aves; porém, até $25 \%$ de inclusão, não diferiu significativamente da ração sem o FIAP.

As variáveis de características de carcaça e os pesos relativos do fígado e do pâncreas de codornas de corte não foram influenciados pelos diferentes tratamentos (Tabela 5). Freitas et al. (2006) avaliaram o efeito da inclusão de um alimento na ração, nas características de carcaça. Os autores observaram que, se o valor nutricional do alimento for bem avaliado, é pouco provável que as características da carcaça sejam influenciadas pela inclusão desse alimento em rações isonutrientes. Entretanto, se o valor de energia metabolizável de um alimento for subestimado, a sua inclusão na ração pode ocasionar mudanças na relação energia:proteína da ração e proporcionar modificações no rendimento e até mesmo nos cortes da carcaça. Nesse contexto, pode-se inferir que o aumento da energia metabolizável da ração com a adição do farelo de arroz não foi suficiente para modificar a relação energia:proteína das rações, ao ponto de promover mudanças significativas nas características da carcaça das codornas, no presente trabalho.

Tabela 4. Desempenho de codornas (Coturnix coturnix) de corte alimentadas com ração contendo farelo integral de arroz parboilizado novo (FIAPN) ou armazenado (FIAPA) por 180 dias.

\begin{tabular}{lccc}
\hline Tratamento & $\begin{array}{c}\text { Consumo } \\
\text { (g por ave) }\end{array}$ & $\begin{array}{c}\text { Ganho de peso } \\
\text { (g por ave) }\end{array}$ & $\begin{array}{c}\text { Conversão } \\
\text { alimentar }\end{array}$ \\
\hline Controle $^{(1)}$ & 660,24 & 220,88 & 2,99 \\
$10 \%$ FIAPA & 639,23 & 219,51 & 2,92 \\
$20 \%$ FIAPA & 650,90 & 230,05 & 2,84 \\
$10 \%$ FIAPN & 663,49 & 222,56 & 2,98 \\
$20 \%$ FIAPN & 654,00 & 231,12 & 2,84 \\
\hline Média & 653,15 & 225,07 & 2,91 \\
CV $(\%)$ & 2,65 & 3,82 & 3,93 \\
\hline Valor p & & & \\
Tratamento & 0,180 & 0,075 & 0,067 \\
Nível & 0,290 & 0,598 & 0,549 \\
Alimento & 0,566 & 0,623 & 0,173 \\
Nível x Alimento & 0,209 & 0,317 & 0,750 \\
\hline
\end{tabular}

${ }^{(1)}$ Controle, sem farelo integral de arroz parboilizado. 
O alto nível de peróxidos na gordura hepática e a presença de muitos dos compostos tóxicos formados durante a oxidação podem provocar danos às células epiteliais do fígado. Além disso, mudanças severas na composição normal de ácidos graxos do fígado causam transtornos no metabolismo dos lipídeos, que resultam em alterações no tamanho deste órgão (Kurir et al., 2004). Desse modo, a ausência de variação no peso relativo do fígado das aves alimentadas com rações contendo FIAPA é um indicativo de que os produtos

Tabela 5. Características da carcaça e pesos relativos do fígado e do pâncreas de codornas (Coturnix coturnix) de corte alimentadas com ração contendo farelo integral de arroz parboilizado novo (FIAPN) ou armazenado (FIAPA) por 180 dias.

\begin{tabular}{lccccc}
\hline Tratamento & $\begin{array}{c}\text { Carcaça } \\
(\%)\end{array}$ & $\begin{array}{c}\text { Coxa+SC } \\
(\%)\end{array}$ & $\begin{array}{c}\text { Peito } \\
(\%)\end{array}$ & $\begin{array}{c}\text { Fígado } \\
(\%)\end{array}$ & $\begin{array}{c}\text { Pâncreas } \\
(\%)\end{array}$ \\
\hline Controle ${ }^{(2)}$ & 66,86 & 24,99 & 41,88 & 1,98 & 0,25 \\
$10 \%$ FIAPA & 68,22 & 24,55 & 42,14 & 1,87 & 0,24 \\
$20 \%$ FIAPA & 67,10 & 24,97 & 42,19 & 1,73 & 0,23 \\
$10 \%$ FIAPN & 68,22 & 24,21 & 41,81 & 1,80 & 0,25 \\
$20 \%$ FIAPN & 68,32 & 24,43 & 41,65 & 1,73 & 0,24 \\
\hline Média & 67,74 & 24,63 & 41,93 & 1,82 & 0,24 \\
CV (\%) & 3,87 & 6,11 & 4,64 & 19,38 & 27,21 \\
\hline Valor p & & & & & \\
$\quad$ Tratamento & 0,406 & 0,578 & 0,942 & 0,310 & 0,978 \\
$\quad$ Nível & 0,473 & 0,401 & 0,905 & 0,299 & 0,748 \\
$\quad$ Alimento & 0,391 & 0,251 & 0,398 & 0,747 & 0,689 \\
Nível x Alimento & 0,393 & 0,797 & 0,837 & 0,714 & 0,968 \\
\hline
\end{tabular}

${ }^{(1)} \mathrm{SC}$, sobrecoxa. ${ }^{(2)}$ Controle, sem farelo integral de arroz parboilizado. secundários e terciários formados no decorrer do processo oxidativo desse farelo não foram suficientes para produzir mudanças no tamanho desse órgão (Tabela 5).

A presença de atividade do inibidor de tripsina no farelo de arroz tem sido associada à hipertrofia do pâncreas de aves (Gallinger et al., 2004). Assim, a ausência de variação no peso relativo do pâncreas (Tabela 5) pode estar relacionada à eficiência do processo de parboilização em inativar o fator antitripsina, presente no farelo de arroz. Mujahid et al. (2003) verificaram que a autoclavagem do farelo de arroz diminui a hipertrofia do pâncreas pela inativação de fatores antiproteolíticos.

$\mathrm{Na}$ análise dos dados dos parâmetros ósseos, constatou-se que os tratamentos não influenciaram comprimento, peso, índice de Seedor, deformidade e resistência da tíbia, bem como quantidade de matéria seca e cinzas nos ossos (Tabela 6).

O ácido fítico e as fibras das dietas têm a capacidade de se ligar a cátions, entre eles, o cálcio e o fósforo, que são os principais minerais da matriz inorgânica do osso, o que não permite que eles sejam completamente utilizados pelas aves (Payne et al., 2005), enquanto o acúmulo de radicais livres, encontrados em gorduras peroxidadas, pode causar disfunção osteoblástica e diminuição da formação óssea (Almeida et al., 2010). No presente trabalho, esses possíveis efeitos não afetaram o crescimento e a qualidade dos ossos das codornas.

Tabela 6. Parâmetros ósseos de codornas (Coturnix coturnix) de corte alimentadas com ração contendo farelo integral de arroz parboilizado novo (FIAPN) ou armazenado (FIAPA) por $180 \operatorname{dias}^{(1)}$.

\begin{tabular}{|c|c|c|c|c|c|c|c|}
\hline Tratamento & $\begin{array}{c}\mathrm{CT} \\
(\mathrm{mm})\end{array}$ & $\begin{array}{l}\text { PT } \\
(\mathrm{g})\end{array}$ & $\begin{array}{c}\text { IST } \\
\left(\mathrm{mg} \mathrm{mm}^{-1}\right)\end{array}$ & $\begin{array}{c}\text { MST } \\
(\%)\end{array}$ & $\begin{array}{l}\text { CZT } \\
(\%)\end{array}$ & $\begin{array}{c}\text { DfT } \\
(\mathrm{mm})\end{array}$ & $\begin{array}{c}\mathrm{RT} \\
\left(\mathrm{kgf} \mathrm{cm}^{-2}\right)\end{array}$ \\
\hline Controle & 57,14 & 1,03 & 18,10 & 69,52 & 50,87 & 1,39 & 2,39 \\
\hline $10 \%$ FIAPA & 56,62 & 1,08 & 19,03 & 66,70 & 48,26 & 1,48 & 2,11 \\
\hline $20 \%$ FIAPA & 56,96 & 1,05 & 18,43 & 66,42 & 48,80 & 1,37 & 2,27 \\
\hline $10 \%$ FIAPN & 56,47 & 1,04 & 18,40 & 68,65 & 49,50 & 1,38 & 2,48 \\
\hline $20 \%$ FIAPN & 57,40 & 1,12 & 19,41 & 69,30 & 48,27 & 1,32 & 2,14 \\
\hline Média & 56,92 & 1,06 & 18,63 & 68,13 & 49,14 & 1,39 & 2,28 \\
\hline CV (\%) & 4,85 & 17,65 & 16,67 & 6,46 & 7,15 & 21,47 & 19,40 \\
\hline \multicolumn{8}{|l|}{ Valor $\mathrm{p}$} \\
\hline Tratamento & 0,901 & 0,772 & 0,802 & 0,189 & 0,259 & 0,723 & 0,136 \\
\hline Nível & 0,225 & 0,701 & 0,882 & 0,840 & 0,801 & 0,347 & 0,649 \\
\hline Alimento & 0,776 & 0,728 & 0,756 & 0,057 & 0,789 & 0,331 & 0,463 \\
\hline Nível x Alimento & 0,570 & 0,375 & 0,392 & 0,702 & 0,396 & 0,755 & 0,072 \\
\hline
\end{tabular}

${ }^{(1)} \mathrm{CT}$, comprimento da tíbia; PT, peso da tíbia; IST, índice de Seedor da tíbia; MST, matéria seca da tíbia; CZT, cinzas da tíbia (expresso na matéria seca); DfT, deformidade da tíbia; RT, resistência da tíbia; Controle, sem farelo integral de arroz parboilizado. 


\section{Conclusão}

O farelo de arroz integral parboilizado armazenado por até 180 dias, mesmo com rancidez, pode ser utilizado na alimentação de codornas (Coturnix coturnix) de corte, no período de 7 a 42 dias de idade, em níveis de até $20 \%$ de inclusão.

\section{Agradecimentos}

À Coordenação de Aperfeiçoamento de Pessoal de Nível Superior (Capes) e ao Conselho Nacional de Desenvolvimento Científico e Tecnológico (CNPq), pelo apoio financeiro e concessão de bolsas.

\section{Referências}

ALMEIDA, M.; HAN, L.; AMBROGINI, E.; BARTELL, S.M.; MANOLAGAS, S.C. Oxidative stress stimulates apoptosis and activates NF-kappaB in osteoblastic cells via a PKCbeta/ p66shc signaling cascade: counter regulation by estrogens or androgens. Molecular Endocrinology, v.24, p.2030-2037, 2010. DOI: $10.1210 /$ me.2010-0189.

BAIÃO, N.C.; LARA, L.J.C. Oil and fat in broiler nutrition. Revista Brasileira de Ciência Avícola, v.7, p.129-141, 2005. DOI: 10.1590/S1516-635X2005000300001.

CHAIYASIT, W.; ELIAS, R.J.; MCCLEMENTS, D.J.; DECKER, E.A. Role of physical structures in bulk oils on lipid oxidation. Critical Reviews in Food Science and Nutrition, v.47, p.299-317, 2007. DOI: 10.1080/10408390600754248.

DORS, G.C.; PINTO, R.H.; BADIALE-FURLONG, E. Influência das condições de parboilização na composição química do arroz. Ciência e Tecnologia de Alimentos, v.29, p.219-224, 2009. DOI: 10.1590/S0101-20612009000100034.

FILGUEIRAS, T.M.D. Uso dos subprodutos do arroz na alimentação de codornas do tipo corte. 2012. 69p. Dissertação (Mestrado) - Universidade Federal do Ceará, Fortaleza.

FREITAS, E.R.; FUENTES, M. de F.F.; SANTOS JÚNIOR, A.; GUERREIRO, M.E.F.; ESPÍNDOLA, G.B. Farelo de castanha de caju em rações para frangos de corte. Pesquisa Agropecuária Brasileira, v.41, p.1001-1006, 2006. DOI: 10.1590/S0100-204X2006000600016.

GALLINGER, C.I.; SUÁREZ, D.M.; IRAZUSTA, A. Effects of rice bran inclusion on performance and bone mineralization in broiler chicks. Journal of Applied Poultry Research, v.13, p.183-190, 2004. DOI: 10.1093/japr/13.2.183.

INSTITUTO ADOLFO LUTZ. Métodos químicos e físicos para análise de alimentos. 4.ed. São Paulo: IMESP, 2008. 1020 p.

KURIR, T.T.; MARKOTIĆ, A.; KATALINIĆ, V.; BOZANIĆ, D.; CIKES, V.; ZEMUNIK, T.; MODUN, D.; RINCIĆ, J.; BORASKA, V.; BOTA, B.; SALAMUNIĆ, I.; RADIĆ, S. Effect of hyperbaric oxygenation on the regeneration of the liver after partial hepatectomy in rats. Brazilian Journal of Medical and Biological Research, v.37, p.1231-1237, 2004. DOI: 10.1590/ S0100-879X2004000800014.

LACERDA, D.B.C.L.; SOARES JÚNIOR, M.S.; BASSINELLO, P.Z.; CASTRO, M.V.L. de; SILVA-LOBO, V.L.; CAMPOS, M.R.H.; SIQUEIRA, B. dos S. Qualidade de farelos de arroz cru, extrusado e parboilizado. Pesquisa Agropecuária Tropical, v.40, p.521-530, 2010. DOI: 10.5216/ pat.v40i4.7266.

LOPES, I.R.V.; FREITAS, E.R.; LIMA, J.R.; VIANA NETO, J.L.; BEZERRA, R.M.; LIMA, R.C. Desempenho e qualidade dos ovos de poedeiras comerciais alimentadas com rações contendo farelo de coco tratado ou não com antioxidante. Revista Brasileira de Zootecnia, v.40, p.2431-2438, 2011. DOI: $10.1590 /$ S1516-35982011001100021.

MUJAHID, A.; ASIF, M.; UL HAQ, I.; ABDULLAH, M.; GILANI, A.H. Nutrient digestibility of broiler feeds containing different levels of variously processed rice bran stored for different periods. Poultry Science, v.8, p.1438-1443, 2003. DOI: $10.1093 / \mathrm{ps} / 82.9 .1438$.

NUTRIENT requirements of poultry. 9.ed. rev. Washington: National Academy Press, 1994. 155p.

OLIVEIRA, M.G. de C.; BASSINELLO, P.Z.; LOBO, V.L. da S.; RINALDI, M.M. Stability and microbiological quality of rice bran subjected to different heat treatments. Ciência e Tecnologia de Alimentos, v.32, p.725-732, 2012. DOI: 10.1590/ S0101-20612012005000095.

PAYNE, R.L.; KAVERGNE, T.K.; SOUTHERN, L.L. A comparison of two sources of phytase in liquid and dry forms in broilers. Poultry Science, v.84, p.265-272, 2005. DOI: $10.1093 / \mathrm{ps} / 84.2 .265$.

PESTANA, V.R.; ZAMBIAZI, R.C.; MENDONÇA, C.R.B.; BRUSCATTO, M.H.; RAMOS, G.R. Influencia del procesado industrial sobre las características químico-físicas y contenido en lípidos y antioxidantes del salvado de arroz. Grasas y Aceites, v.60, p.184-193, 2009. DOI: 10.3989/gya.075108.

PIYARATNE, M.K.D.K.; ATAPATTU, N.S.B.M.; MENDIS, A.P.S.; AMARASINGHE, A.G.C. Effects of balancing rice bran based diets for up to four amino acids on growth performance of broilers. Tropical Agricultural Research and Extension, v.12, p.57-61, 2009

ROSTAGNO, H.S.; ALBINO, L.F.T.; DONZELE, J.L.; GOMES, P.C.; OLIVEIRA, R.F. de; LOPES, D.C.; FERREIRA, A.S.; BARRETO, S.L.T.; EUCLIDES, R.F. Tabelas brasileiras para aves e suínos: composição de alimentos e exigências nutricionais. 3.ed. Viçosa: Ed. da UFV, 2011. 252p.

SAKOMURA, N.K.; ROSTAGNO, H.S. Métodos de pesquisa em nutrição de monogástricos. Jaboticabal: Funep, 2007. $283 p$.

SAMLI, H.E.; SENKOYLU, N.; AKYUREK, H.; AGMA, A. Using rice bran in laying hen diets. Journal of Central European Agriculture, v.7, p.135-140, 2006.

SEEDOR, J.G.; QUARTUCCIO, H.A.; THOMPSON, D.D. The bisphosphonate alendronate (MK-217) inhibits bone loss due to 
ovariectomy in rats. Journal of Bone and Mineral Research, v.6, p.339-346, 1991. DOI: 10.1002/jbmr.5650060405.

SILVA, D.J.; QUEIROZ, A.C. de. Análise de alimentos: métodos químicos e biológicos. 3.ed. Viçosa: Ed. da UFV, 2002. 235p.
SILVA, M.A. da; SANCHES, C.; AMANTE, E.R. Prevention of hydrolytic rancidity in rice bran. Journal of Food Engineering, v.75, p.487-491, 2006. DOI: 10.1016/j. jfoodeng.2005.03.066.

Recebido em 20 de março de 2014 e aprovado em 20 de maio de 2014 